\title{
Clinicopathological Features of Colorectal Cancer at the Extremes of Age
} JM Plummer, D Ferron-Boothe, PA Leake, S Hamilton, L Powell, N Meeks-Aitken

\begin{abstract}
Objective: To determine the clinicopathological features of patients with colorectal cancer (CRC) at the extremes of age and compare differences across the younger and older age groups.

Method: Data was obtained from the CRC Registry for patients diagnosed during the 4-year period commencing January 1, 2011. Variables analyzed included clinical presentation, tumour site, stage, various histopathologic features and adequacy of nodal resection.

Results: Of 900 cases entered into our database, 59 were age 40 and under and 119 were age 80 and over ( $7 \%$ and $13 \%$ respectively). These patients were referenced with patients diagnosed between age 50-70 years and they formed the basis of this study. Common clinical presentations across both groups were bleeding per rectum (26\% vs $17 \%$ ), change in bowel habits (both $31 \%$ ) and abdominal pain (16\% vs 14$)$, with no statistical difference between groups $(\mathrm{P}=0.556)$. Most tumours occurred in the rectum (27\%) and the sigmoid colon (26\%) with $72 \%$ of all tumours being moderately differentiated. Comparison across age groups revealed equivalent tumour distribution. However, younger patients had more signet ring histology $(15 \%$ vs $4 \% ; \mathrm{P}=0.035)$ while there was a trend towards older patients having perineural invasion $(15 \% \mathrm{vs} 7 \% ; \mathrm{P}=0.088)$. All categories of patients had similar tumour $(\mathrm{T})$ stage while significantly more nodes were examined for younger patients $(\mathrm{P}=$ 0.002). The number of positive nodes did not differ between the two extremes $(\mathrm{P}=0.500)$.
\end{abstract}

Conclusions: This review demonstrates that while there are a few measurable differences in CRC in patients at the extremes of age, most patients were overall similar in their clinical symptoms, tumour distribution and stage at diagnosis.

Keywords: Colorectal cancer, elderly, young, locally advanced

From: Department of Surgery, Radiology, Anaesthesia and Intensive Care, Faculty of Medical Sciences, University of the West Indies, Kingston 7, Jamaica.

Correspondence: Dr J Plummer, Department of Surgery, Radiology, Anaesthesia and Intensive Care, Faculty of Medical Sciences, The University of the West Indies, Kingston 7, Jamaica.

Fax: 1-876- 9704302, e-mail: joseph.plummer02@uwimona.edu.jm 


\section{INTRODUCTION}

Colorectal cancer $(\mathrm{CRC})$ is the third commonest cancer in the Jamaican population and the third leading cause of cancer death in both men and women in most western countries $(1,2)$. Its incidence increases with age (3) but approximately $20 \%$ of the cases seen occur in patients under 50 years (4). As with most western countries, Jamaica enjoys an acceptable quality of health care and life expectancy is increasing with current average survival age of 76 years for women and 74 for men. It is therefore expected that we will continue to see an increasing number of CRC patients over age 70. Compared to the average risk individuals, patients with early onset CRC generally have a poorer outcome (5) whilst those presenting over age 80 years, albeit that there are challenges with surgical management because of associated co-morbidities, tend to do better (6). This may be because the tumours are biologically less aggressive $(7,8)$.

Screening is generally recommended commencing at age 50 for average risk patients but there is no universally set upper age limit to discontinue screening. Using colonoscopy as a screening tool the average patient may only need two or three such examinations because after age 70, routine screening is generally not practiced (11). Screening is the best means of preventing CRC or detecting it at an early stage so that it can be cured with surgery only. Often the presentation of symptomatic disease is at an advanced stage thus surgery is one aspect of a multimodal approach to effect cure or at least to prolong life. Given the absence of recommendations regarding routine screening of patients at the extremes of ages (11), it is likely that they often present with symptomatic disease.

One obvious risk factor justifying early onset screening is a strong family history of CRC affecting first-degree relatives or of early onset suggestive of a hereditary or familial cancer syndrome such as Lynch syndrome where screening is suggested about a decade earlier than 
average risk individuals. Establishing other means of identifying members of the population who fall outside the 'average-risk' group but will develop CRC would facilitate selective, costeffective screening in these patient groups. The purpose of this study was to evaluate the clinicopathological features of CRC at the extremes of age and to compare differences across the younger and older age groups. They may also be compared with other CRC patients who qualify for screening by virtue of their age in an attempt to identify unique features that may account for their presentation at these ages.

\section{PATIENTS AND METHODS}

Data was obtained from the Colorectal Cancer Registry maintained at the University Hospital of the West Indies (UHWI) that uses CnEXT software to prospectively enter all cases of CRC diagnosed from the major treating hospitals throughout Jamaica, the details of which have been previously published (9). All cases entered during the four-year period January 2011-December 2014 were identified and evaluated for inclusion. For analysis purposes patients were considered young if they were age 40 and under, elderly if at the time of their diagnosis they were age 80 and above and these were referenced with the average screenable age patients diagnosed between 50-70 years that could be seen as a control group. Patient demographics, presenting symptoms, tumour location, depth of tumour and nodal status and other prognostic tumour indicators, such as margins, degree of differentiation, perineural and lymphovascular invasion, were examined. These were then compared across the two groups. Ethical approval for data collection was approved by the University Hospital of the West Indies/Faculty of Medical Sciences Ethics Committee. 


\section{Statistics}

Data were summarized and Chi - square tests of association were conducted to compare the distributions of categorical variables across age groups. Wilcoxon ranksum tests were conducted to compare numerical variables across age groups with a $\mathrm{p}$ value $<0.05$ considered significant.

\section{RESULTS}

During the four-year period, a total of 900 cases were entered into the registry. Of this total, 59 (7\%) were patients aged 40 and younger whilst $119(13 \%)$ were aged 80 and older. Included during this period were 417 patients between ages 50-70 years at the time of their diagnosis. Comparison of the patients was done between those aged 40 and younger and aged 80 and older this formed the basis of this report. Table 1 summarized the characteristics of this sample. Female-to-male distribution was 1.2:1. Most (72\%) tumors were moderately differentiated. The three most common primary sites for the tumor were the rectum $(27 \%)$, ascending colon $(26 \%)$, and the sigmoid colon (23\%). Eighty percent of the tumors were adenocarcinoma not otherwise specified (NOS) histology.

Tables 2 and 3 shows the comparison of histologic details and pathologic staging of tumor characteristics across groups. Most characteristics were similar across the age categories. However, a larger proportion of patients at the older extreme had tumors displaying perineural invasion $(7 \%$ vs. $15 \% ; p=0.088)$ and lymphovascular invasion $(p=0.067)$. The number of other pathologies found in non-tumour bowel was significantly different across the extremes of age with $31 \%$ of patients 80 and older having more than two compared with only $9 \%$ of patients 40 and younger $(\mathrm{p}=0.010)$. The histology of tumors was also significantly different at the two 
extremes of age. Younger patients had a larger proportion of tumors with mucinous/signet ring histology $(15 \%$ vs. $4 \% ; p=0.035)$, while older patients had a larger proportion of tumors with adenocarcinoma NOS histology ( $87 \%$ vs. $74 \%$ ). The mean tumour size was $92.7 \mathrm{~mm}$ vs 107.8 $\mathrm{mm}(\mathrm{p}=0.745)$ while median depth of invasion was similar across both groups (T3). The median number of nodes examined in tumors among persons at the younger group was approximately seven more than the number examined among persons at the older extreme (median 17 vs $10.5 ; \mathrm{p}=0.002$ ). Despite examining significantly more nodes among younger patients, the number of nodes positive for metastatic disease did not differ between the two extremes $(\mathrm{p}=0.500)$. Overall, pathology of the primary tumor $(\mathrm{T}$-stage) trended towards significance $(\mathrm{P}=0.089)$ across the extremes of age. Approximately one - quarter $(24 \%)$ of patients at the younger extreme of age had tumors with a T-stage of 1 or 2 compared to only $8 \%$ of patients at the older extreme having a tumor with a T-stage of 1 or $2(\mathrm{p}=0.155)$.

\section{DISCUSSION}

Colorectal cancer is an important cause of cancer-related morbidity and mortality in our population and surgery has a central role in curing or alleviating the symptoms of those affected. While surgery is one aspect of a multimodal approach for the majority of patients with this disease, with the exception of some cases of rectal cancer (10), its performance is the only hope for cure or any long-term palliation of symptoms. 
A review of our cases shows that most of our group was in the older age group and most tumours were moderately differentiated and located in the left colon as previously documented (8). Pathologic characteristics were similar across the age groups except more mucinous or signet ring tumours were found in the younger age group and with the greater possibility or finding other pathologies in the non-tumourous bowel in the older age group. The latter is not an unexpected finding as diverticulosis, for example, is very common in octogenarians and the presence of polyps does increase with age. There was a trend towards the elderly patients having more perineural and lymphovascular involvement. Perineural and lymphovascular invasion are associated with advanced CRC and are independent poor prognostic marker for survival (12). As a group, the majority of the cases were locally advanced T3NI disease and qualified for adjuvant therapy.

Comparison across the age groups also revealed that the tumours had similar sizes and nodal involvement, perhaps an indication of their protracted preclinical phase before diagnosis. That the younger patients had more nodes resected is possibly an attempt by the surgeon to ensure a complete lymphadenectomy that has had its limitations in our population $(13,14)$. A more extensive colectomy being performed in the younger age group may also account for the difference. This is an acceptable approach especially for the hereditary colorectal cancers like Lynch Syndrome, which is present in our population (15).

The absence of additional clinical data limits this report and the histopathologic features are more alike than different. The clinical presentation may not be particularly different given similar tumour distribution and pathological stage. Perhaps, evaluation at the molecular level is necessary to unveil significant differences. Overall although this report has limitations by incomplete data in some categories and the retrospective nature of a registry dataset still it 
demonstrated that there were subtle differences in the pathological features of CRC across the ages. However these results suggest that in our population CRC patients at the extreme of age are presenting with equally advanced disease and no uniquely identifying clinical features. It therefore requires high clinical vigilance and the early but judicious use of various diagnostic investigations in managing the minimally symptomatic patient.

\section{CONCLUSIONS}

In our population most of the clinicopathological features of colorectal cancer in the young and elderly patients are similar to the features of the disease in the screenable age groups, presenting often times with locally advanced disease. This supports the importance of high clinical vigilance and timely use of diagnostic investigations in all patients with CRC symptoms.

\section{ACKNOWLEDGEMENTS}

Funding for this study was supported by the University of the West Indies New Initiative Grant (15065P). The authors would also like to thank Dr Ayesha Johnson for her assistance with statistical analysis.

\section{AUTHORS' NOTE}

Study concept and design: JM Plummer, PA Leake, L-P Powell 
Data collection: D Ferron-Boothe, N Meeks-Aitken

Data analysis and manuscript writing: JM Plummer, S Hamilton, PA Leake, L-P Powell

All authors contributed to and approved of the final version of this manuscript. The authors declare no conflict of interest.

\section{REFRENCES}

1. Gibson TN, Blake G, Hanchard B, Waugh N, McNaughton D. Age-Specific Incidence of Cancer in Kingston and St. Andrew, Jamaica, 1998-2002. West Indian Med J, 2008; 57: $81-9$.

2. $\quad$ Siegel R, Naishadham D, Jemal A. Cancer statistics, 2012. CA Cancer J Clin. 2012; 62: $10-29$.

3. Andereggen E, Ris F, Gervaz P, Bucher P, Morel P. Outcome of surgery for rectal cancer in octogenarians. Swiss Med Wkly 2006; 136: 185-8. 
4. André M, Bouchardy C, Fioretta G, Lutz JM, Neyroud-Caspar I, Obradovic M, et al. Le cancer à Genève. Incidence, mortal- ité, survie 1970-1998, Registre Genevois des Tumeurs, Genève, 2003.

5. McFarlane MEC, Plummer JM, Leake PA, Williams NP, Ferron-Boothe D, MeeksAitken N. Colorectal cancer in Jamaica: patterns and anatomical distribution. West Indian Med J 2014 (Suppl 4); 63: 48.

6. JM Plummer, N Williams, S Gallinger, S Chin, R Graham, G Wharfe et al. Colorectal cancer in young patients in Jamaica: are there genetic factors unique to this population? West Indian Med. J. 2009; 58 (Suppl 4) 46.

7. Limpert P, Longo WE, Kelemen PR, Vernava AM, Bahadursingh AN, Johnson FE et al. Colon and rectal cancer in the elderly. High incidence of asymptomatic disease, less surgical emergencies, and a favorable short-term outcome. Crit Rev Oncol Hematol 2003; 48:159-63.

8. McFarlane MEC, Rhoden A, Fletcher PR, Carpenter R. Cancer of the Colon and Rectum in a Jamaican Population. Diagnostic Implications of the Changing Frequency and Subsite Distribution. West Indian Med J 2004; 53: 170.

9. Plummer JM, Williams N, Leake P-A, Ferron-Boothe D, Meeks-Aitken N, Mitchell DI et al. Surgical quality in colorectal cancer. Ann Surg Med 2016; 5: 52-6.

10. Smith JJ, Garcia-Aguilar J. Advances and challenges in the treatment of locally advanced rectal cancer. J Clin Oncol 2015; 33: 1797-808.

11. Lee MG. Colon cancer screening. West Indian Med J 2006; 55: 365. 
12. Al-Sukhni E, Attwood K, Gabriel EM, LeVea CM. Kanehira K, Nurkin SJ. Lymphovascular and perineural invasion are associated with poor prognostic features and outcome in colorectal cancer: A retrospective cohort. Int J Surg 2017 ; 37: 42-9.

13. Parsons HM, Tuttle TM, Kuntz KM, Begun JW, McGovern PM, Virnig BA. Quality of care along the cancer continuum: does receiving adequate lymph node evaluation for colon cancer lead to comprehensive postsurgical care? J Am Coll Surg 2012; 215: 40011.

12. RPD Graham, JM Plummer, KA West, NP Williams. Adequacy of lymph node harvesting in colorectal cancer management: Improving standards, ensuring quality. West Indian Med J 2012; 134-8.

13. JM Plummer, N Williams, S Chin, R Graham, G Wharfe, M Aaronson et al. Lynch syndrome in a predominantly Afrocentric population: a clinicopathological and genetic study. Can J Surg. 2012; 55: 294-300.

Table 1: Comparison of patient clinical characteristics across age groups

\begin{tabular}{|c|c|c|c|}
\hline \multirow[t]{2}{*}{ Characteristics } & \multicolumn{3}{|c|}{ Age at Diagnosis } \\
\hline & $\begin{array}{c}40 \& \\
\text { younger } \\
(\mathrm{N}=59)\end{array}$ & $\begin{array}{c}50-70 \\
(\mathrm{~N}=417)\end{array}$ & $\begin{array}{r}80 \\
\text { old } \\
(\mathbf{N}= \\
\end{array}$ \\
\hline \multicolumn{4}{|l|}{$\operatorname{Sex}(p=0.372)$} \\
\hline Female & $58 \%$ & $49 \%$ & $53 \%$ \\
\hline Male & $42 \%$ & $51 \%$ & $45 \%$ \\
\hline \multicolumn{4}{|c|}{ Clinical presentation $(p=0.793)$} \\
\hline BRBPR/LGIB & $25 \%$ & $22 \%$ & $18 \%$ \\
\hline Abdominal pain & $10 \%$ & $11 \%$ & $14 \%$ \\
\hline H/O cancer or Polyp & $34 \%$ & $38 \%$ & $35 \%$ \\
\hline
\end{tabular}


Other

Primary site $(\mathrm{p}=0.759)$

Cecum

Right/ascending colon/hepatic flexure transverse colon

left/descending colon/splenic flexure

Sigmoid

colon NOS

Rectum/Rectosigmoid

Non-tumours bowel $(\mathrm{p}=0.010)$

2 or less

More than 2

of NOS $=$ not otherwise specified
$29 \%$

$24 \%$

$30 \%$

$\begin{array}{lll}3 \% & 6 \% & 4 \% \\ 22 \% & 22 \% & 29 \% \\ 5 \% & 3 \% & 3 \% \\ 8 \% & 8 \% & 8 \% \\ 22 \% & 21 \% & 24 \% \\ 12 \% & 7 \% & 5 \% \\ 27 \% & 33 \% & 27 \%\end{array}$

$\begin{array}{lll}53 \% & 48 \% & 40 \%\end{array}$

$2 \% \quad 10 \% \quad 15 \%$

$\mathrm{BRBPR}=$ bright red blood per rectum; $\mathrm{LGIB}=$ lower gastrointestinal haemorrhage; $\mathrm{H} / \mathrm{O}=$ history

Table 2: Comparison of patient pathological characteristics across age groups

\begin{tabular}{|c|c|c|c|}
\hline Age at Diagnosis & $\begin{array}{l}40 \text { \& } \\
\text { Under } \\
(N=59)\end{array}$ & $\begin{array}{l}50-70 \\
(N=417) \\
\end{array}$ & $\begin{array}{l}80 \& \\
\text { Older } \\
(N=119) \\
\end{array}$ \\
\hline \multicolumn{4}{|l|}{ Histology $(p=0.035)$} \\
\hline Adenocarcinoma NOS & $71 \%$ & $77 \%$ & $84 \%$ \\
\hline $\begin{array}{l}\text { Adenocarcinoma in tubular/tubulovillous } \\
\text { adenoma }\end{array}$ & $3 \%$ & $7 \%$ & $5 \%$ \\
\hline Mucinous/Signet Ring & $15 \%$ & $7 \%$ & $4 \%$ \\
\hline
\end{tabular}


Other

Grade differentiation $(\mathrm{p}=0.928)$

Well

Moderate

poor

Crohn-like reaction
$7 \% \quad 9 \% \quad 3 \%$

$7 \% \quad 10 \% \quad 9 \%$

$73 \% \quad 70 \% \quad 71 \%$

$8 \% \quad 10 \% \quad 10 \%$

$14 \% \quad 16 \% \quad 16 \%$

Perineural invasion $(\mathrm{p}=0.088)$

Yes

$7 \% \quad 12 \% \quad 15 \%$

Lymph vascular invasion $(\mathrm{p}=0.067)$

Present

$15 \% \quad 20 \% \quad 22 \%$

NOS $=$ not otherwise specified;

Table 3: Comparison of tumour staging variables across age groups

\begin{tabular}{llcl}
\hline Characteristics & \multicolumn{2}{l}{ Age at Diagnosis } \\
& $\begin{array}{l}\mathbf{4 0} \boldsymbol{\&} \\
\text { Under }\end{array}$ & $\mathbf{5 0 - 7 0}$ & $\mathbf{8 0} \&$ Older \\
\hline $\begin{array}{lll}\text { Pathology T-stage }(\mathrm{p}=0.155) \\
1 \text { or } 2\end{array}$ & & & \\
3 or 4 & $12 \%$ & $8 \%$ & $3 \%$ \\
& $37 \%$ & $45 \%$ & $38 \%$
\end{tabular}




$\begin{array}{llll}\begin{array}{l}\text { Median depth of invasion } \\ \text { (T-stage) }\end{array} & 3 & 3 & 3 \\ \text { Pathology N-stage }(\mathrm{p}=0.217) & & & \\ 0 & 20 \% & 27 \% & 21 \% \\ 1 & 20 \% & 13 \% & 13 \% \\ 2 & 7 \% & 12 \% & 6 \%\end{array}$

No. of nodes examined $\mathrm{P}=$

0.002

Mean + sd

$20.6+15.3 \quad 15.4+10.0$

$11.8+6.3$

Median

17

13.0

10.5

Some percentages do not sum to 100 due to missing data

$\mathrm{T}=$ tumour; $\mathrm{N}=$ nodes 